\title{
Investigation of Generic and Subject-Specific Learning Preferences of First-year Medical Students
}

\author{
Mustafa Serdar Koksal, Kubra Acikgul, Recep Aslaner \\ Department Inonu University, Faculty of Education, Department of Elementary Education 44280, \\ Campus/Malatya, Turkey
}

\section{ARTICLE INFO}

Received

: 23/01/2013

Accepted : :07/03/2013

Published : :01/09/2013

\section{KEYWORD}

Learning styles

Medical students

Subject based learning

\section{ABSTRACT}

Objective: In this study, the purposes are to investigate generic and subjectspecific learning preferences of first-year medical students, and to examine whether any significant association exists between generic and subjectspecific learning preferences (math and science subjects). Method: In the study, 120 first-year medical students $($ Male $=48$, Female=57, Missing data for gender variable $=15$ ) were surveyed by using two instruments (VARK Questionnaire, Question Form on Learning Ways in Science and Math). Two different analyses were done; one for generic preferences and one for subject-specific preferences. For the analyses, frequencies and percentages were calculated, and then Spearman rho value was calculated for analyzing relationship. Results: The findings showed that $50 \%$ of the participants were unimodal in their general learning preference. When looked at the subject-specific learning preferences, it was seen that $31 \%$ of the participants preferred unimodal learning preferences for learning sciencerelated subjects. For mathematics subjects, $45 \%$ of the participants preferred unimodal learning preferences. The relationship between generic and subject-specific learning preferences was non-significant while the relationship between math and science-related learning preferences was significant. Conclusion: The findings point out that majority of the medical students preferred unimodal learning preferences among four learning modes (unimodal, bimodal, trimodal, quadmodal). In addition, subjectspecific and generic learning preferences of the participants differ from each other when learning preferences are considered by focusing learning task. Moreover, there is no direct association between generic and subjectspecific learning preferences while learning preferences regarding science and math subjects are correlated with each other.

(C) Medical Education Department, School of Medical Sciences, Universiti Sains Malaysia. All rights reserved.

CORRESPONDING AUTHOR: Mustafa Serdar Koksal, Inonu University, Faculty of Education, Department of Elementary Education 44280, Campus/Malatya, Turkey. Email: bioeducator@ gmail.com 


\section{Introduction}

In teaching about medical issues as for other types of issues, instructors need to know about learning preferences of learners at the outset to make instruction more appropriate to learning preferences of students. Learning preferences is defined as predispositions of learners to perceive, process and recall information when it is required, in a certain way or combination of different ways [1]. Some studies show importance of designing instruction in line with student learning preferences to meet requirements of increasing motivation and performance of students [2,3]. Gurpinar, Bati and Tetik point out that learning preference of medical students interact with teaching models; using educational methods that favor learning preferences of medical students has a potential to facilitate learning [4]. McManus, Richards, Winder and Sproston studied on the relationship between gain in clinical experiences and learning preferences of medical students, they found that amount of knowledge gain from clinical experience is related to learning preferences of medical students [5]. In a recent study, Dobson, by giving attention to effect of establishing correspondence between learning preferences and instruction on class scores, found higher scores of auditory learners on overall class score on a medical subject (physiology) than the learners having other types of learning preferences when the type of instruction was lecture in medical teaching [6]. Moreover, learning preferences of medical students are good predictors in determining effectiveness of the curriculums used in medical education, thus correspondence between learning preferences and teaching method is an important task in planning medical teaching [7]. In the literature, there are different learning preference models and instruments [8-11]. As one of the information-processing based models, VARK (Visual, Auditory, Read/Write and Kinesthetic) is frequently used for the studies with medical students [12-14]. Fleming, developer of the model, mentions about four types of sensory modalities including visual, auditory, read/write and kinesthetic modalities in the model for taking in new information [13]. Visual learners prefer to learn from pictures, graphs and charts while auditory learners learn about something by listening and discussing. The learners having "Read/write" learning preference learn by reading textbooks and text-based handouts. The "Kinesthetic" learning preference involves learning by touching or manipulating the materials [13]. Not only might students use one modality but also they can prefer to use multiple modalities. The studies conducted with medical students show that majority of the medical students have multimodal learning preferences despite the fact that some studies represent 50\% of the medical students have unimodal learning preferences $[12,14,15]$.

Medical instructors should meet educational needs of all students in learning different subjects by considering their learning preferences in medical teaching during which both general preferences and subject-specific preferences are in case. Fleming's model might be a good beginning for determining general learning preferences, but in giving detailed feedback for teaching to medical students, the model is not sufficient, because teaching medical subjects is not limited to general situations such as finding a place by using a particular learning preference [13]. Fleming also does not see the preferences as stable personality characteristics that are valid for every learning situation and emphasizes use of the model as a beginning point in dialog between students and instructors for designing coherent instruction in line with learning preferences of medical students [16].

Up to now, studies on learning preferences of medical students have been done to determine general VARK preferences rather than investigating both general preferences and subject-specific preferences of medical students $[12,14,17,18]$. However medical teaching does not involve only general learning situations, it involves both science-related and mathematicsrelated subjects in addition to social sciences and clinical applications. Drysdale, Ross and Schulz have stated that different learning subjects or disciplines require different learning preferences [19]. Science and math-related learning is a basic requirement for entering and following a medical 
education since both of the subjects cover basic concepts and conceptual structures of medical sciences.

The medical teaching is not a homogenous process including only one type of subjects and learning tasks, since content (subjects) and order of the subjects change over years and learning preferences for each subject should also change because of these changes. When looked at all learning experiences in medical teaching, both subject-free and subject-specific learning preferences are seen to be potential influential factor on learning. Therefore, getting detailed information about learning preferences of medical students in the first-years should be made in two different levels; general learning preferences including VARK modalities and specific learning preferences regarding to subjects (science and math). Investigation of learning preferences in two different levels and, the relationship between subject-specific (science and math) learning preferences and VARK preferences might provide more detailed and meaningful understanding of learning preferences of first-year medical students to inform medical instructors.

The purpose of this study is to investigate learning preferences of first-year medical students and, if there is a relationship between generic and subject-specific learning preferences of them.

\section{Method}

\section{Study Design}

In this study, cross-sectional survey method was used to investigate the problems of the study. To collect data, two different instruments (VARK Questionnaire and Question Form on Learning Ways in Science and Math) were distributed to 220 participants, 120 accepted to participate in the survey, so the instruments were applied to 120 first-year medical students (Male $=48$, Female $=57$, Missing=15) enrolled in two different medical schools of two different middle-scale universities of Turkey. The approval rate of the participants to participate in the study was 55\% (120/220). The medical education in Turkey includes six or seven-year programs, the first three years are for the basic sciences while the remained years include clinical experiences and internship. The most preferred teaching ways in the courses include pure lecturing and lecturing with visuals [20]. Data collection was conducted in Medical Biology and Genetics course in spring semester of 2012. Before data collection, consent forms approved by ethics authorities were given to the students for learning about their willingness to participate in the study.

\section{Instruments}

Two different instruments were utilized in this study; VARK Questionnaire and Question Form on Learning Ways in Science and Math. VARK questionnaire identifies modes of taking information; it has 16 items on different generic learning situations. In answering the questions, the participants can omit some questions or select two or more options. The Turkish version (7.1) of the questionnaire was taken via web pages of VARK (http://www.varklearn.com/english/index.asp and http://www.vark learn.com/documents/The\%20VARK\%20Questi onnaire $\% 20-\% 20$ Turkish. pdf). The validity evidence on the VARK instruments was provided by Leite, Svinicki and Shi [21]. This instrument was chosen for its conciseness, easy administrability and frequently use for medical students. Second instrument (Questions form) used in this study was designed for the purpose of this study and involved six different learning questions (three for science and three for mathematics). In the instrument, "cell", "structure of atom" and "electric circuit" subjects for science-specific learning and "sets", "functions" and "right prism and pyramids" subjects for mathematics learning are included. These subjects are chosen from high school subjects who are common to all participants and are subjects of nation-wide examination to enter medical programs. At the same time, medical students should be competent on these subjects for being successful in their future learning on medical subjects. In the questionnaire, as an example "how do you learn "cell" subject?" is 
asked to the students and this question is also asked for other five subjects after the modification of the question for related subject. The data collected by the question form have qualitative nature.

\section{Analysis}

Data collected by VARK was analyzed by using scoring sheet, applying classification rules of VARK and dividing number of the students in one category into total number of responses to find the percentage of students in each category. In addition, some categories had small number of the students; the data regarding them was presented as frequency in total number of the students.

For analyzing the data on learning preferences regarding the subjects, all of the answers of the participants were coded for emerging learning preferences by using open coding in which codes emerged over the time of analysis. In coding process two different researchers coded the answers independently and they reached 93.3\% agreement on the codes regarding science and mathematics learning preferences. 90\% agreement is accepted enough to advocate validity of the data $[22,23]$. Twenty four codes for both science-related and mathematics-related subjects were determined (see table 1). Then, codes were put into relevant VARK categories and codes which were not related to any VARK mode were named as "others". After putting the codes into VARK modes, analysis of the data was done by dividing number of the students in

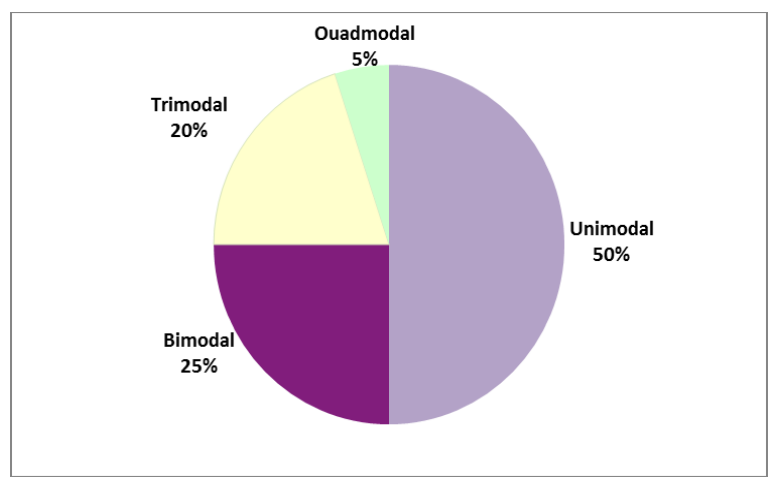

one category into total number of responses to find the percentage of students in each category.

For analyzing a possible relationship between VARK preferences and subject-specific learning preferences, Spearman rho correlation was conducted to find whether there was a relationship between generic (VARK) and subject-specific learning preferences. For the analysis, alpha level was set as .01.

\section{Result}

The results of this study are represented in three aspects; VARK preferences, subject-specific learning preferences and relationship between VARK preferences and subject-specific learning preferences, they are represented under two different titles.

\section{Results on Learning Preferences Based on VARK Results}

In the Figure 1, the percentages of students who preferred unimodal (50\%) and multimodal (50\%) learning modes in VARK are presented. Among multimodal learners, bimodal learning preference has been preferred with the highest percentage. When looked at the Figure 1, it is obvious that auditory learners have the highest percentage among the students having unimodal learning preferences.

Figure 1: Percentages of the students who preferred unimodal and multimodal learning preferences and percentages of the students preferring the specific unimodal learning preferences. 
In Figure 2, percentages of the students who preferred multimodal learning preferences show that "AK (Auditory/ Kinesthetic)" "VAK (Visual/Auditory/ Kinesthetic)" and "ARK (Auditory/Read-Write/ Kinesthetic)" learning preferences are more preferred by the multimodal learners than other types of multimodal learning preferences.

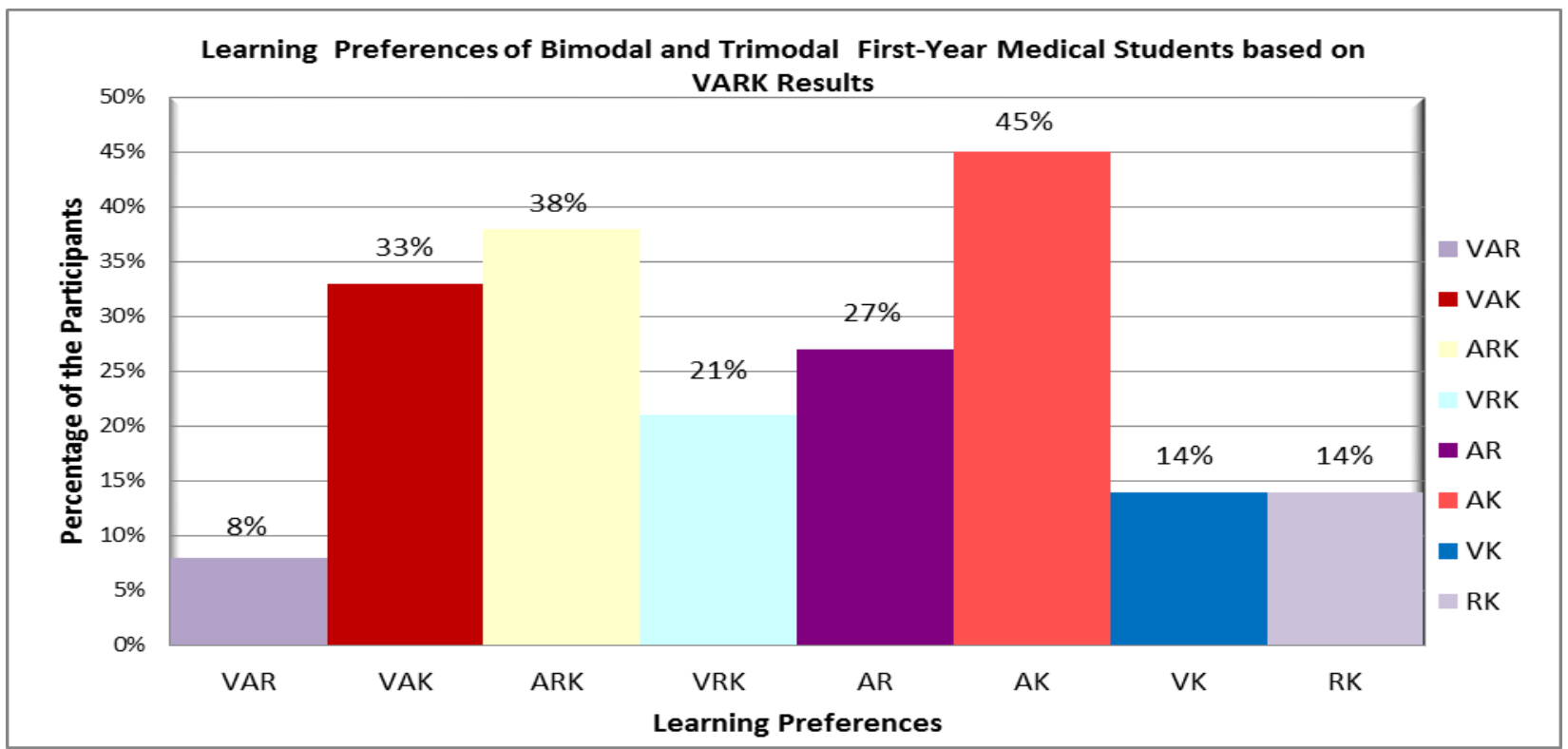

Figure 2: Percentages of the students preferring specific multimodal learning preferences

\section{Results on Subject-Specific Learning Preferences}

In addition to generic (VARK) learning preferences, subject-specific learning preferences of the students were also determined. Table 1 represents frequencies of codes for learning preferences regarding science and mathematics subjects. At the same time, the codes which corresponded to a VARK mode were grouped under the VARK modes. The grouped and ungrouped codes are represented in Table 1.

Table 1: Specific Learning Preferences of First-Year Medical Students on Science and Mathematics Related Subjects

\begin{tabular}{lllllll}
\hline \multirow{2}{*}{$\begin{array}{l}\text { VARK } \\
\text { and Others }\end{array}$} & Categories & $\begin{array}{l}\text { Learning } \\
\text { (Codes) }\end{array}$ & Preferences & Science & \multicolumn{3}{c}{ Mathematics } \\
\cline { 2 - 6 } & & $\mathbf{F}$ & $\mathbf{\%}$ & $\mathbf{F}$ & \% \\
\hline Visual & Using Visuals & 32 & 7,98 & 14 & 4,55 \\
\cline { 2 - 6 } & Imagination & 8 & 2,00 & 25 & 8,12 \\
\cline { 2 - 6 } & Table Construction & 1 & 0,25 & 1 & 0,32 \\
\cline { 2 - 6 } & Drawing & 22 & 5,49 & 15 & 4,87 \\
\hline Auditory & Listening & 38 & 9,48 & 31 & 10,06 \\
\hline Reading/Writing & Reading & 40 & 9,98 & 12 & 3,90 \\
\cline { 2 - 6 } & Writing & 29 & 7,23 & 12 & 3,90 \\
\hline
\end{tabular}




\begin{tabular}{|c|c|c|c|c|c|}
\hline & $\begin{array}{l}\text { Rehearsal on Subject by } \\
\text { Written Materials }\end{array}$ & 38 & 9,48 & 13 & 4,22 \\
\hline & Personal Studies Using Books & 46 & 11,47 & 37 & 12,01 \\
\hline & Memorization & 8 & 2,00 & 8 & 2,60 \\
\hline & $\begin{array}{l}\text { Solving Problem Questions in } \\
\text { Textbooks }\end{array}$ & 46 & 11,47 & 76 & 24,68 \\
\hline \multirow[t]{3}{*}{ Kinesthetic } & Making Applications & 32 & 7,98 & 4 & 1,30 \\
\hline & Experiential Learning & 1 & 0,25 & not included & 0 \\
\hline & Touching & $\begin{array}{l}\text { not } \\
\text { included }\end{array}$ & 0 & 1 & 0,32 \\
\hline \multirow[t]{13}{*}{ Others } & $\begin{array}{lll}\text { Making Investigations } & \text { on } \\
\text { Books, Questions etc. } & \end{array}$ & 26 & 6,48 & 17 & 5,52 \\
\hline & Classification & 5 & 1,25 & 4 & 1,30 \\
\hline & $\begin{array}{l}\text { Talking to Others about the } \\
\text { Subject }\end{array}$ & 3 & 0,75 & 1 & 0,32 \\
\hline & Giving Meanings & 1 & 0,25 & 2 & 0,65 \\
\hline & $\begin{array}{l}\text { Making Connection with the } \\
\text { Past }\end{array}$ & 1 & 0,25 & 7 & 2,27 \\
\hline & Using Models & 4 & 1,00 & 8 & 2,60 \\
\hline & Formula Production & $\begin{array}{l}\text { not } \\
\text { included }\end{array}$ & 0 & 1 & 0,32 \\
\hline & Formula Adaptation & $\begin{array}{l}\text { not } \\
\text { included }\end{array}$ & 0 & 1 & 0,32 \\
\hline & Encoding & 1 & 0,25 & not included & 0 \\
\hline & Comparing & 1 & 0,25 & not included & 0 \\
\hline & Taking Help of Others & 14 & 3,49 & 11 & 3,57 \\
\hline & Asking Questions & 3 & 0,75 & 7 & 2,27 \\
\hline & Using Internet & 1 & 0,25 & not included & 0 \\
\hline
\end{tabular}

The results on subject-specific learning preferences indicate that the highest frequency of preferences for both science and mathematics learning is for reading/writing preference. In the results presented in Table 1, the important point is to know total frequency regarding the codes. In total, 401 frequencies under the codes related to learning on science subjects and 308 frequencies under the codes for learning on mathematics related subjects are calculated. The finding on the code named as "Making Investigations on Books, Questions etc." showed relatively high frequency, but in Turkish "making observations" is too general for describing an action. For example; only looking the pages, reading sentences, making comparisons among different sources in terms of figures, sentences and examples, solving problems in sources are regarded as "investigation" actions. Thus, this code was separated from certain VARK codes. In Figure 3, the preferences of the students for learning science-related and math-related subjects are presented 


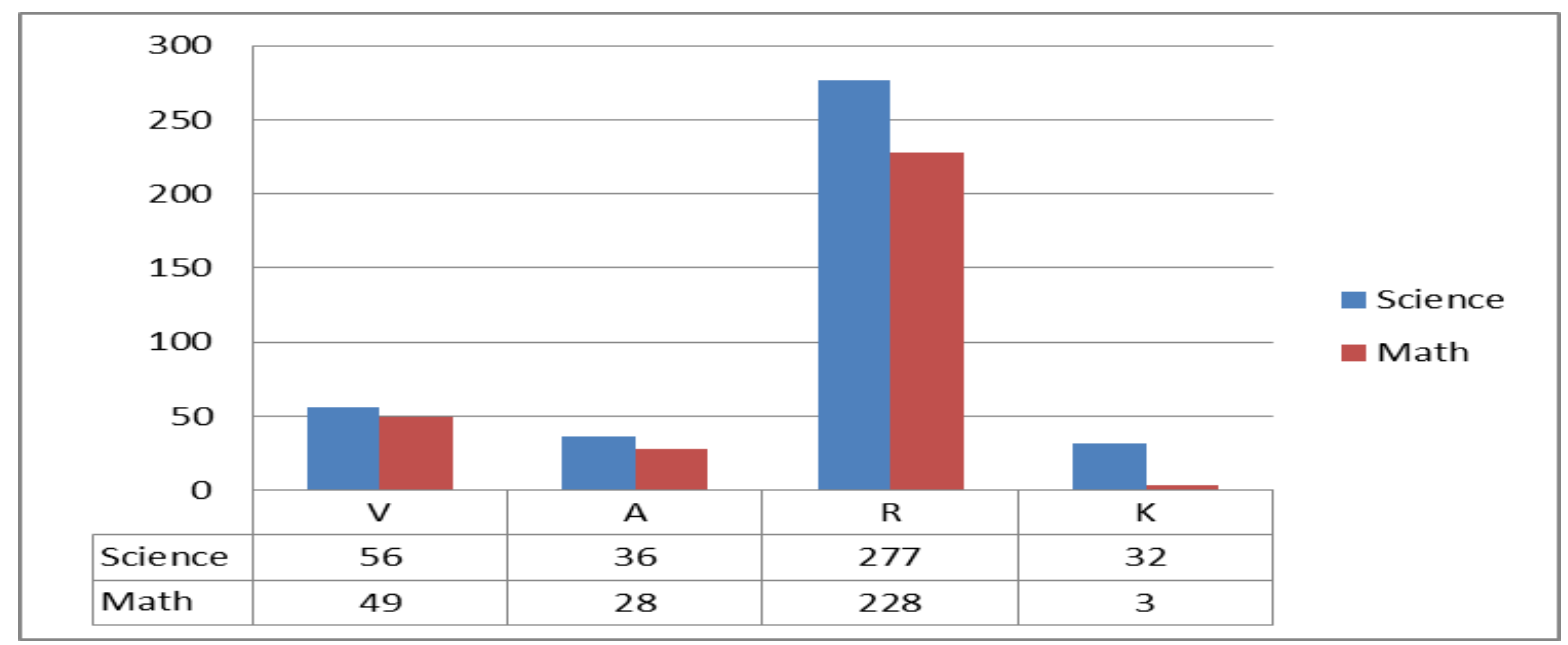

Note: Total number of code frequencies for science learning is 401 (Number of codes $=24$ ) and total number of code frequencies for math learning is 308 (Number of codes $=24$ ).

Figure 3: Percentages of the students preferring unimodal learning preferences regarding science and mathrelated subjects.

After the codes were analyzed as a separate data set, they were also analyzed for the percentages of the students after VARK categorization. Figure 4 represents percentages of the students who preferred unimodal and multimodal learning preferences regarding science-related and mathrelated subjects.

According to the results represented in Figure 4, $69 \%$ of the participants are multimodal learners on science-related subjects. Also, majority of unimodal learners have reading/writing preference to learn science subjects. For mathematics-related subjects, $55 \%$ of the students preferred multimodal learning mode. As seen in Figure 4, majority of unimodal learners also preferred reading/writing mode to learn mathematics subjects.

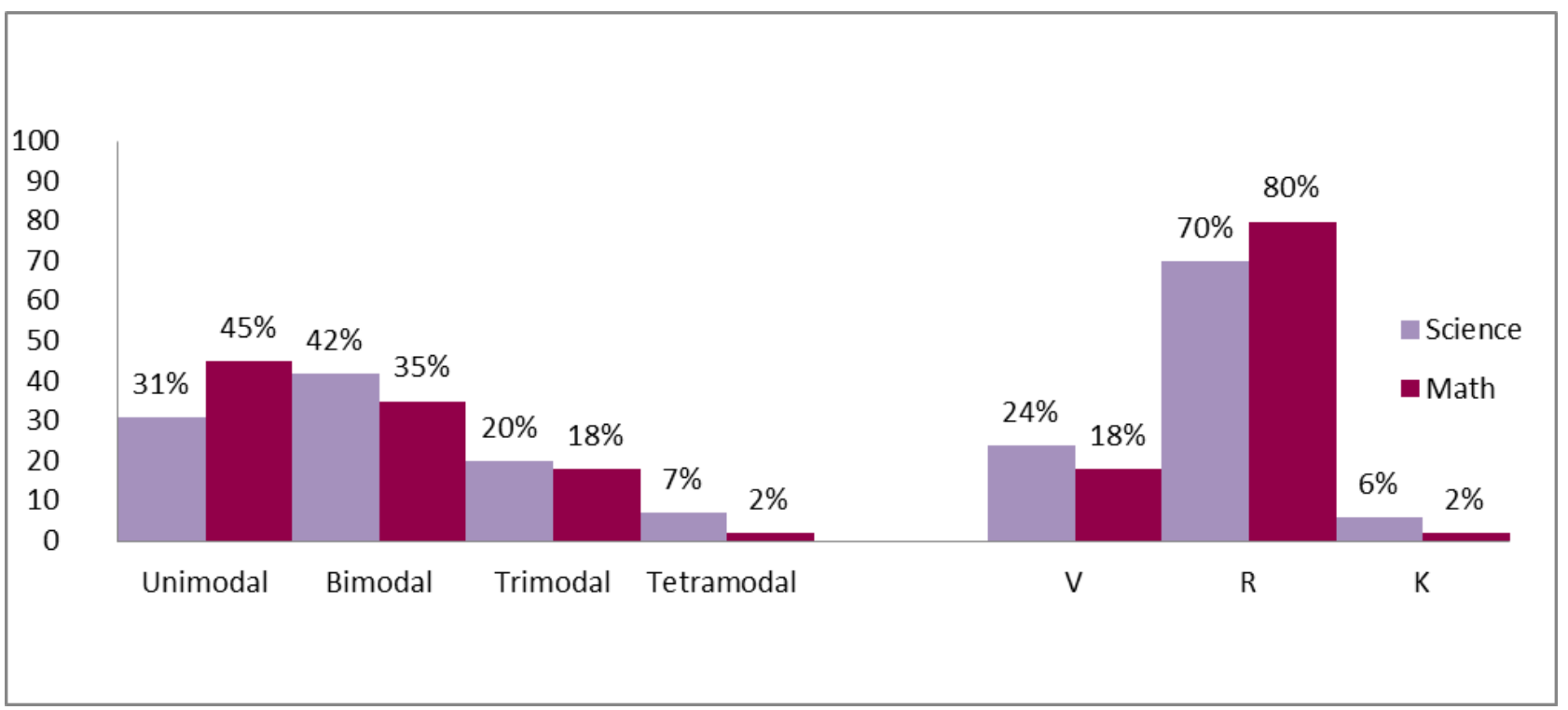

Figure 4: Percentages of the students preferring unimodal and multimodal learning preferences regarding science and math-related subjects based on VARK categorization. 
In Figure 5, frequencies of the students having bimodal and trimodal learning preferences in learning science and mathematics subjects are presented. "AR" and "VR" preferences are chosen for science-related learning by majority of multimodal learners while "AR" and "VAR" are preferred for learning math-related subjects by majority of multimodal learners.

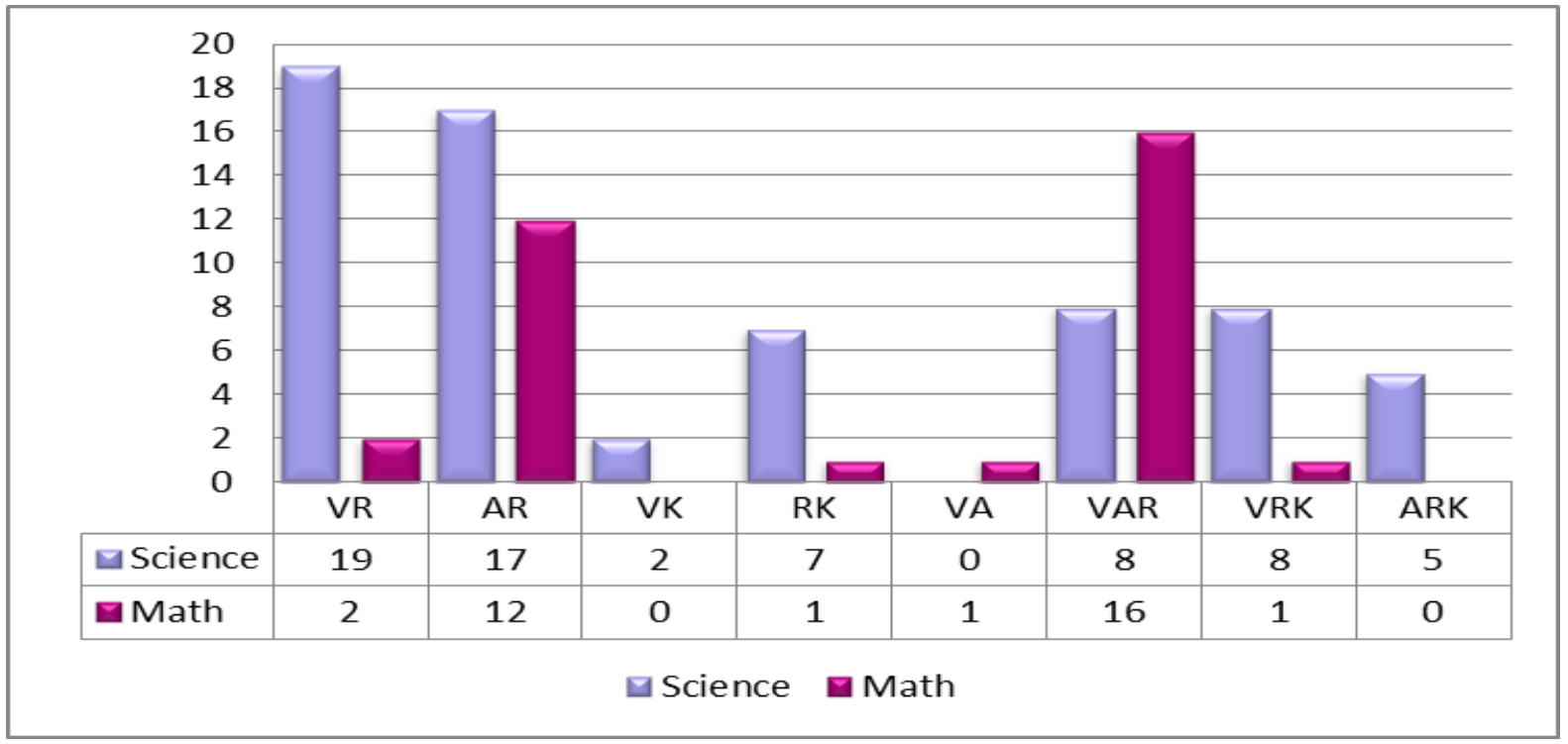

Figure 5: Frequencies of the students preferring multimodal learning preferences regarding science and math-related subjects based on VARK categorization.

The final analysis on the data was made to investigate a possible relationship between subject-specific and generic (VARK) learning preferences. The results on Spearman correlation analysis (see table 2) showed that there was no significant relationship between generic (VARK) and subject-specific learning preferences of the medical students for both science and mathematics, but there was a significant relationship between learning preferences of the students for learning science and mathematics subjects $(\mathrm{Rho}=.31, \mathrm{p}<.01)$.

Table 2: Spearman Correlation Results on Relationship between Learning Preferences of First-Year Medical Students on Science and Mathematics Related Subjects, and Generic Learning Preferences

\begin{tabular}{llll}
\hline Analysis Pair & $\mathrm{N}$ & Rho & $p$ \\
\hline Learning Preferences on Science- Learning Preferences on Math & 120 & .31 & $<.01$ \\
\hline Learning Preferences on Science- Generic Learning Preferences & 120 & .15 & $>.01$ \\
\hline Learning Preferences on Math- Generic Learning Preferences & 120 & -.18 & $>.01$ \\
\hline
\end{tabular}




\section{Discussion and Conclusion}

The major findings of the study showed that the percentage of the students who preferred unimodal learning preferences on VARK categorization was equal to the percentage of the multimodal learners. But subject-specific learning preferences represented different situation in which majority of the students preferred multimodal learning preference for learning science and mathematics subjects. This difference might be related to level of measurement; generic (VARK) or subjectspecific. As stated by Fleming and Baume, learning preferences of the students are not stable personality characteristics; it can be changed over time and for different subjects [16]. Heterogeneous nature of learning in terms of content and order of the subjects also supports the finding that there is a difference between generic learning preferences and subject or taskspecific learning preferences [24]. Moreover, Drysdale, Ross and Schulz supported this finding by stating that different learning subjects or disciplines require different learning preferences [19].

In the literature, proportion of unimodal learners on VARK categories are represented differently by different studies [12, 15, 17]. This contradiction might be related to cultural differences and nature of the instrument (lack of validation and reliability [9]). Of all participants, $51.4 \%$ unimodal learning preferences among Malaysian medical students was determined by Kumar, Voralu, Pani and Sethuraman [15]. Malaysia is similar to Turkey in terms of religious background and cultural heritage; hence the similarity in generic learning preferences might be based on similar generic experiences in similar culture. In spite of similarity with Malaysian culture, a study conducted in identical culture with this study showed a different finding [12]. When looked at the results of Baykan and Nacar's study conducted in Turkish culture, the problem related to validity and reliability emerges as more powerful explanatory factor for the difference of our finding from finding of Baykan and Nacar [12]. Hence, the result on this difference between these two studies should be examined by considering validation and reliability of the instrument (VARK questionnaire).

As another aspect of this study, no relationship between subject-specific learning preferences and generic learning preferences was found while there was a significant relationship or correspondence between learning preferences for science and math-related learning. This finding supports the idea of existence of more levels of learning preferences than one generic level; one for subject-specific learning and one for generic learning. The relationship between subjectspecific learning preferences also shows existence of partial similarities for learning preferences in learning science and mathematics subjects. Both mathematics and science subjects are learned in similar schooling culture in Turkey. Nonetheless, they have different contents and different reasoning modes, these differences might also contribute to the differences among learning preferences of the students.

The VARK results on the unimodal learners pointed out auditory learning preference as dominant learning way of the participants while the students who preferred unimodal learning preferences in learning subject-specific information selected "read/write" mode of learning. This finding shows the difference in the unimodal preferences when you measure the preferences at different levels. Difference in learning preferences for generic and subjectspecific learning also occurs for multimodal learners. Based VARK results, "ARK" and "AK" were found as the most preferred modes of learning in generic situations but in learning subject-specific information "VAR" and "AR" were found as the most preferred learning modes for both science and math learning. At the same, "VR" learning mode preference was found among the most preferred preferences for learning science-related subjects.

Generic learning is rooted from the experiences in daily life in a particular culture while subject- 
specific learning is based on specific experiences regarding educational background, examinations and materials frequently used in formal educational processes and formal education culture. When you asked about "how can you find the way for a building you do not know about?", the students have a tendency to use similar ways of their cultural partners. However, for the question of "how can you learn about human tissues?", the students need to find a way to learn a new information by using different resources provided by teachers or peers who are members of a narrow culture (educational cultural). For the generic learning, dominancy of "auditory" mode might be explained with frequent use of listening for learning about generic situations in our culture. However, dominance of "read/write" mode of learning for science and mathematics learning might be explained with frequent use of books and notes for learning in our formal schools from elementary schools to universities.

Based on the results of this study, it can be said that medical teaching, at least, involves two levels of learning; generic and subject-specific. The relationship analysis warned us about significant relationship between subject-specific learning preferences while it also informed us about no relationship between generic and subject-specific learning preferences. Hence, there is a need to inform instructors about learning preferences of the students in two different levels. By this way, instructors might prepare their courses in line with learning preferences of the students on generic and subject-specific learning situations. At the same time, decisions about the degree of unimodality and multimodality in course applications might be made by considering nature of learning situations in medical teaching.

As an important implication of the findings of this study, there is evidence that pure lecturing or lecturing with visuals are not enough to help learning of medical students having multimodal learning preferences. The findings also point out that learning in medical courses cannot be limited to one mode of learning, the instructors should give attention two levels of learning preferences (generic and subject-specific) in their plans for teaching. At the same time, the findings of this study warns us about making detailed subject analysis for finding appropriate ways of representing subjects effectively in medical courses.

With these important findings, the current study has some limitations. The sample of the study is limited to 120 participants, so generalization of the study should be made on this basis. The study should be done by increasing number of the participants who are randomly selected from the population. At the same time, the data collected by the VARK questionnaire need further evidence in terms of both reliability and validity since the instrument provides categorical data on which factor analysis cannot be applied. The findings of the study on VARK results should be examined carefully. Also, the VARK questionnaire in future studies should be applied to the participants with an additional learning style inventory which has validity and reliability evidence based on factor analysis or further techniques. This way of application might give evidence about validity and reliability of the VARK questionnaire when the correlation between the instruments is found high enough.

\section{Reference}

1. Sarasin LL. Learning Style Perspectives: Impact in the Classroom. Madison, WI: Atwood Publishing, 1998.

2. Brown B. Myths and Realities No. 26: Teaching Style vs. Learning Style, Columbus, OH: Educational Resources Information Center, 2003.

3. Murphy RJ, Gray SA, Straja SR, Bogert MC. Student learning preferences and teaching implications. J Dent Educ 2004; 68; 859-866.

4. Gürpınar E, Bati AH, Tetik C. Learning styles of medical students change in relation to time. Adv Physiol Educ 2011; 35; 307311.

5. McManus IC, Richards $\mathrm{P}$, Winder BC, Sproston, KA. Clinical experience, performance in final examinations, and learning style in medical students: Prospective study. BMJ 1998; 316; 345-350.

6. Dobson JL. Learning style preferences and course performance in an undergraduate 
physiology class. Adv Physiol Educ 2009; 33; 308-314.

7. Van der Veken J, Valcke M, Muijtjens A, De Maeseneer J, Derese A. The potential of the inventory of learning styles to study students' learning patterns in three types of medical curricula. Med Teach 2008; 30; 863-869.

8. Cassidy S. Learning Styles: An overview of theories, models, and measures. Educational Psychology: An International Journal of Experimental Educational Psychology 2004; 24; 419-444.

9. Hawk TF, Shah AJ. Using learning style instruments to enhance student learning. Decision Sciences Journal of Innovative Education 2007; 5; 1-19.

10. Kolb DA. Experiential learning: Experience as the source of learning and development, New Jersey, Prentice-Hall Publication, 1984.

11. Myers-Briggs I. The Myers-Briggs Type Indicator manual, Prinecton, NJ: Educational Testing Service, 1962.

12. Baykan Z, Nacar M. Learning styles of firstyear medical students attending Erciyes University in Kayseri, Turkey. Adv Physiol Educ 2007; 31;158-160.

13. Fleming ND. 1995. I'm different; not dumb. Modes of presentation (VARK) in the tertiary classroom. In: Zelmer A (eds.). Research and Development in Higher Education: Blending Tradition and Technology. Proceedings of the 1995 Annual Conference of the Higher Education and Research Development Society of Australasia, Jul 4-8 1995 Australia. Volume 18 , pp. $308-313$.

14. Slater JA, Lujan HL, DiCarlo SE. Does gender influnce learning style preference of first-year medical students? Adv Physiol Educ 2007; 31; 336-342.

15. Kumar LR, Voralu K, Pani SP, Sethuraman KR. Predominant learning styles adopted by AIMST university students in Malaysia. South East Asean Journal of Medical Education 2009; 3; 37-46.

16. Fleming N, Baume D. Learning Styles Again: VARKing up the right tree!. Educational Developments, SEDA Ltd, Issue 7; 4-7, 2006.

17. Lujan HL, DiCarlo SE. First-year medical students prefer multiple learning styles. Adv Physiol Educ 2006; 30; 13-16.

18. Alkhasawneh IM, Mrayyan MT, Docherty C, Alashram S, Yousef HY. Problem-based learning (PBL): assessing students' learning preferences using VARK. Nurs EducToday 2008; 28; 572-579.

19. Drysdale MTB, Ross JL, Schulz RA. Cognitive learning styles and academic performance in 19 first-year university courses: successful students versus students at risk. Journal of Education for Students Placed at Risk 2001; 6; 271-289.

20. Uskun E, Doğan M, Kişioğlu AN, Baylan S, Uzun E, Akaya VB. Süleyman Demirel Üniversitesi tıp fakültesi öğretim üyelerinin tıp eğitimi ile ilgili düşünce ve uygulamaları. Süleyman Demirel Üniversitesi Tip Fakültesi Dergisi 2004; 3;19-24.

21. Leite WL, Svinicki, M, Shi Y. Attempted validation of the scores of the VARK: learning styles inventory with multitraitmultimethod confirmatory factor analysis models. Educational and Psychological Measurement 2010; 70; 323-339.

22. Neuendorf KA. The Content Analysis Guidebook, Thousand Oaks, CA, Sage Publication, 2002.

23. Artstein R, Poesio M. Inter-coder agreement for computational linguistics. Comput Linguist 2008; 34; 555-596.

24. Ashby FG, Ell SW. The neurobiology of human category learning. Trends Cogn Sci 2001; 5; 204-210. 